\title{
LA PRESENCIA DE LOS INMIGRANTES Y DEL PROCESO DE INMIGRACIÓN EN LA PRENSA GRATUITA BARCELONESA: ESTUDIO EXPLORATORIO
}

\author{
Maria Luiza Martins de Mendonça \\ (Universidade Federal de Goiás, Brasil) \\ ma.luisa@terra.com.br
}

\section{Resumen:}

El artículo es resultado de una investigación exploratoria realizada tras el análisis de dos periódicos gratuitos distribuidos en la ciudad de Barcelona, con el objetivo de identificar el tratamiento que estos periódicos dispensan a los inmigrantes y a los procesos de migración. Se parte del principio de que la forma de representar estos colectivos opera como constructor de sentido e incide sobre la percepción que los lectores construyen respecto a los procesos de representación, así como de los individuos o colectividades de extranjeros.

Palabras clave: Medios de comunicación, diarios gratuitos, minorías, inmigrantes.

\begin{abstract}
:
This research is a study on the treatment found in two periodicals of the so-called "free press", Metro and ADN, all distributed in the city of Barcelona. This work is aimed at evaluating the manner in which these vehicles produce and reproduce the role and socially circulating conceptions about the different social groups, in this specific case the immigrants, in an attempt to identify the values attributed to them and the social places they can legitimately desire and effectively occupy.
\end{abstract}

Keywords: Media, free press, minority groups, immigrants.

\section{MEDIOS DE COMUNICACIÓN Y MINORÍAS: LAS FORMAS DE REPRESEN- TACIÓN}

on muchas las cuestiones relacionadas con la representación y la expresión de grupos minoritarios en los diferentes medios de comunicación que merecen la atención del investigador, debido a la importancia teórica y empírica que adquieren cuando se considera que los medios de comunicación son, en gran parte de las sociedades contemporáneas, los grandes constructores culturales y que ocupan un lugar central en las disputas por la hegemonía y por la fijación de los dos significados sociales. De modo teórico es importante reconocer que las disputas políticoideológicas ocurren también en la esfera de la producción cultural y que los sentidos 
La presencia de los inmigrantes y del procesos de inmigración en la prensa...

que circulan socialmente son construcciones históricas estables, pero, de ninguna manera, permanentes. Los significados atribuidos a los diferentes grupos sociales son índices de los lugares que ocupan en el conjunto de las representaciones sociales, de los valores que se les atribuyen y también de las distintas maneras de percibirlos, representarlos y de construir concepciones respecto de ellos.

Esa investigación trata sobre un estudio exploratorio referente al tratamiento que dos periódicos pertenecientes a la denominada prensa gratuita, Metro Catalunya y $A D N$, distribuidos en la ciudad de Barcelona dan a los temas relativos a los inmigrantes o a la inmigración. De esta forma, se pretende evaluar la manera cómo esos medios producen y/o reproducen el papel y las concepciones socialmente circulantes sobre los diversos grupos sociales, en ese caso específico los inmigrantes, e identificar los valores que les son atribuidos, así como los lugares sociales que pueden legítimamente desear y efectivamente ocupar. En las sociedades que se pretenden democráticas, los diferentes grupos pueden aspirar a dividir en igualdad de condiciones tanto los espacios de poder como los productos resultantes del proceso económico: materiales y simbólicos. Contribuir para conocer mejor esas relaciones de poder y los procesos en que se fundamentan o legitiman es siempre un procedimiento necesario para facilitar el desarrollo de estrategias comunicativas que propicien posibilidades efectivas de democratización de las relaciones sociales.

\section{LAS MIGRACIONES COMO PROBLEMA}

A pesar de que el fenómeno migratorio está históricamente relacionado a la presencia del ser humano en la tierra y ser causa del proceso de población de todos los continentes, en las últimas décadas el desarrollo de los medios de comunicación y del transporte contribuyó tanto para poblar el imaginario de colectividades enteras con sueños de otra vida como para proporcionar los medios materiales necesarios para atravesar largas distancias ${ }^{1}$.

Si bien se puede constatar un cierto agotamiento en las discusiones sobre las características y consecuencias de los procesos de globalización que inciden de maneras diferenciadas sobre las distintas naciones y segmentos poblacionales, no se puede dejar de mencionar que los procesos migratorios han sufrido una gran expansión. Las pérdidas de poder de los gobiernos nacionales, en general mayores en países pobres y con pocas perspectivas de crecimiento económico, las políticas mundiales de racionalización de los procesos de producción y distribución de riquezas agravaron la situación de grandes contingentes poblacionales que se encuentran al margen del proceso productivo y no vislumbran la posibilidad de una existencia digna en términos materiales y, mucho menos, de algún tipo de ascensión social. La realidad de guerra, miseria, hambre y el bloqueo de alternativas y aspiraciones individuales tan presentes en numerosos países, desde África hasta Irak, pasando por Oriente Medio y por los Balcanes, transforman los países desarrollados en polos extremadamente atractivos para la inmigración. En respuesta a eso, países pertenecientes a la Comunidad Europea y a la América desarrollada, como Estados Unidos

\footnotetext{
${ }^{1}$ Puede parecer irónica la referencia a la tecnología en ese momento, pero en la España actual se asiste a la llegada de emigrantes en cayucos, pateras, aviones, navíos de lujo.
} 
y Canadá, blindaron sus fronteras para impedir la entrada de inmigrantes indeseados. Sin embargo, el fenómeno es visible y perceptible, independientemente de las estadísticas demográficas: está en las calles de las grandes ciudades, en los centros y en las periferias.

Las ciudades, actualmente, se han transformado en local de encuentro entre las consecuencias de una globalización, que pone en movimiento constante recursos, ideas e individuos y el extranjero, el diferente, el Otro. De acuerdo con Bauman (2006: 61), son las ciudades las que tienen que administrar y ofrecer soluciones para los problemas causados por la expansión global del capitalismo, como la creación de masas de individuos sin lugar en las nuevas maneras de producción tecnológicas. Son esos desplazados por las miserias y falta de perspectiva quienes aportan a las grandes ciudades del mundo desarrollado, llevando consigo la esperanza de una supervivencia algo más digna.

Es en las ciudades donde el fenómeno se hace visible, en la presencia física de individuos marcadamente extraños, sea por el color de la piel, por el acento o idioma hablado, por las maneras de vestirse, de alimentarse, de comportarse. Estos nuevos habitantes, que provocan resistencias en la población local en la medida que aumentan las demandas y dejan en evidencia las carencias de los servicios públicos básicos, son los que se someten a subempleos y desvelan las insuficiencias de los sistemas de inclusión social. Además, a medida que los ciudadanos locales se deparan con lo nuevo, con aquello que muchas veces parece no identificable e indescifrable, ellos ven amenazada la pretendida estabilidad que las solidaridades anteriores eran capaces de proporcionar. En tales circunstancias, no es del todo incomprensible que aparezca el temor y el rechazo a esa convivencia cotidiana y que mecanismos de repulsión, más o menos evidentes, sean puestos en acción. Es en ese sentido, que importa intentar conocer un poco mejor las dinámicas de las formas de expresión de las diferencias y desigualdades que se basan en los diferentes orígenes geográficos. Aquello que las refuerza, las posibles conexiones entre diferencias raciales y otros tipos de distinción, sean ellas de origen social, cultural, religioso, económico o de orientación sexual, así como las diferentes manifestaciones o expresiones de rechazo. En términos teóricos, el abordaje se pauta por una perspectiva que considera el fenómeno de las migraciones como algo relevante para comprender las formas como son articuladas las diferencias entre los diferentes grupos en las sociedades contemporáneas, principalmente en las grandes ciudades.

Es también en las grandes ciudades donde se disemina un nuevo modelo de medio masivo de comunicación, la llamada prensa gratuita, periódicos en formato tabloide y distribuidos gratuitamente en puntos de mayor concentración de personas, en general en los medios públicos de transporte. Esos diarios se autoproclaman los periódicos del siglo XXI y comenzaron a ser producidos y distribuidos de forma masiva a partir del comienzo del siglo coincidiendo con la disminución del número de electores de los tradicionales periódicos de pago. Esa modalidad de comunicación llama la atención del investigador por tratarse de un fenómeno nuevo y de largo alcance, aún poco estudiado en lo que concierne a su capacidad de producción y reproducción de significados sociales, entendiendo que sus contenidos sean relevantes para la formación de opiniones y construcciones de visiones de mundo. Interesa, por lo tanto, evaluar esa prensa diaria, nueva, gratuita, que tiene como lector el individuo joven y sin el hábito de lectura de los periódicos de pago, es decir, el 
La presencia de los inmigrantes y del procesos de inmigración en la prensa...

individuo que prácticamente no posee otras fuentes de información alternativas y complementarias. Es posible que la amplitud de su circulación y la diseminación entre un público anteriormente distante de la prensa escrita hayan generado la posibilidad de tornarlos medios alternativos a los discursos estereotipados de los medios de comunicación tradicionales.

En ese caso, la investigación intenta evaluar la perspectiva con que la prensa gratuita aborda la cuestión de la inmigración. ¿Cuál es el tratamiento que da al inmigrante, considerando el tratamiento como la forma en que lo presenta, lo relaciona con los valores?

En primer lugar, es necesario definir mejor lo que se entiende por prensa gratuita y cuáles serían las particularidades que la hacen relevante para un análisis que tenga en perspectiva la construcción de significados alrededor de emigrantes y migraciones. Estos diarios se caracterizan por ser gratuitos, se entregan directamente al lector, poseen un formato apropiado para permitir una lectura rápida, más o menos de acuerdo con el tiempo promedio del traslado entre la casa y el trabajo. Para ello, los contenidos son generalistas, superficiales y fáciles de leer, con muchas fotos e informaciones gráficas. Cuentan con secciones bastante diversificadas como forma de agradar a intereses heterogéneos. Se abstienen del partidismo político-ideológico y, al mismo tiempo en que ofrecen una idea de lo que esta sucediendo en el mundo y en el país, dedican un espacio generoso a las noticias locales, con muchas fotos e identificación de los protagonistas, en el sentido de crear proximidad y familiaridad con el lector. Al mismo tiempo llevan al lector noticias que no caben en los periódicos tradicionales, permiten que la publicidad llegue a segmentos de la población que no son objetivo de la gran prensa y se vuelve un medio más atractivo para los anunciantes locales. Proveen informaciones que se juzgan útiles por el lector, tales como horarios, atracciones artísticas y culturales. De acuerdo con los propios editores, es el distanciamiento tanto de la política partidaria como de la publicidad excesiva lo que confiere credibilidad al periódico. Pero lo que más se puede destacar en esta nueva modalidad de medio impreso es su alcance: se difunde básicamente entre lectores jóvenes que no tenían el hábito de leer periódicos diarios. De este modo, se conquistó un nuevo lector.

Algunos de esos diarios son propiedad de grandes empresas multinacionales y están presentes en varios países, adoptando la estrategia de aliarse a socios locales. Uno de los mayores, Metro, es parte de la multinacional sueca Metro Internacional S/A y posee casi 20 millones de lectores en todo el mundo. El otro, 20 Minutos, pertenece al grupo noruego Schilbsted y tiene fuerte presencia en los países escandinavos, Francia, Suiza y España.

Según la investigación realizada por el periódico 20 Minutos (2001: 211), el perfil de los lectores indica un equilibrio entre los sexos, y una franja de edad en que el $60 \%$ de los lectores cuentan con menos de 44 años de edad. En cuanto al número de lectores, se estima que el Metro, mayor periódico con circulación internacional, posee más de 18 millones de lectores, de los cuales 1,9 millones en España.

Las principales suposiciones que orientan esta investigación consideran que esos periódicos, así como los demás medios de comunicación, perciben el fenómeno de 
la inmigración y la presencia de inmigrantes en las ciudades españolas de una manera estereotipada, desde el punto de vista de las particularidades y de las diferencias culturales, con lo étnico como motivo central; reafirman la noción de multiculturalismo como pensamiento hegemónico; $y$, en determinados momentos lo relacionan veladamente o no, con amenazas al pueblo y al orden establecido. A pesar de que esa perspectiva no se presenta de forma explícita en lo cotidiano, ella se vuelve absolutamente declarada en momentos de crisis o de toma de decisiones sobre políticas públicas de mayor alcance.

Inicialmente se había propuesto también la hipótesis de la existencia de diferentes niveles de racismo, o sea, de la existencia de racismos diferenciados a medida que se combinan con otros demarcadores de diferencias, como la clase social, el origen geográfico, el color de la piel, por ejemplo. Sin embargo, el informe de la investigación titulado Avance de los resultados de la encuesta realizada por el Instituto de Estudios Sociales de Andalucía para la Secretaria de Estado de Inmigración de España ya identifica esa diferenciación en los grados de rechazo. Es necesario ahora identificar si la prensa gratuita refuerza o no esos mismos patrones de rechazo. Cuando fueron interrogados sobre el origen de los inmigrantes, los entrevistados identificaron, en el siguiente orden: los latinoamericanos, los árabes y los sub-saharianos. La percepción de la existencia de los extranjeros debe ser relacionada también con la visibilidad que adquiere cierta comunidad, no apenas por su presencia cuantitativa, su presencia en las calles, en el transporte público, en los locales de trabajo y ocio, fácilmente identificable a medida en que está explicitada por medio del color de la piel o por los trazos fisonómicos, sino también por la visibilidad de esos individuos en los medios de comunicación.

El contenido analizado fue el de la portada de cada edición, con su correspondiente reportaje en las páginas interiores. Consideramos la portada como un elemento de análisis revelador, ya que es programada para llamar la atención del lector para determinado asunto más que para otros. Según Van Dijk,

La portada, el tamaño, el tipo de titulares, la utilización de determinados tamaños de fuente o de negrita, las fotografías y otras propiedades en la presentación de un noticiero expresan significados subyacentes y jerarquías semánticas que, a su vez, son instrumento para la formación de modelos (de concepción de mundo) por parte del lector. Por lo tanto, y como estrategia general, los actores más notables y sus actividades se presentan de forma más prominente, es decir, en la portada, en su parte superior, en los titulares, en la sección de sucesos destacados y, si se trata de portavoces, en la categoría de reacciones verbales dentro del esquema de un informe (Van Dijk, 1997: 62).

Más allá de esto, al destacar una noticia, acontecimiento o personaje, el periódico señala la importancia de los mismos, lo que es captado y reconocido como relevante por el lector.

En términos metodológicos, el concepto de tratamiento se refiere al valor que la información atribuye a los protagonistas y tiene como objetivo identificar el posicionamiento ideológico, sociocultural, político y económico que los medios colocan en la esfera pública. Este tratamiento valorativo puede ser aprehendido por medio de relaciones que se establecen entre los sujetos protagonistas de las noticias y una va- 
La presencia de los inmigrantes y del procesos de inmigración en la prensa...

riedad de identificadores: instituciones, valores sociales, calificación, la existencia de fotos y destacados gráficos, la existencia de relaciones de contigüidad, complementación o de contradicción entre las noticias/fotos publicadas. El concepto de tratamiento incluye más de un punto de vista, más allá de la emisión del mensaje: incorpora la producción (las rutinas productivas, la obediencia a los manuales de redacción y estilo), el proceso de recepción y utilización de los mensajes como elementos que, incorporados a los discursos personales/sociales son capaces, o no, de promover el diálogo y contribuir para la dinamización de las relaciones interculturales ${ }^{2}$.

Son varios los elementos que componen una noticia y están presentes en la narrativa periodística. Hay elementos visuales, como fotos, gráficos o ilustraciones, el tamaño y la página /sección en que la noticia se publica, los protagonistas principales, la existencia o no de entrevistas, las fuentes citadas, los valores atribuidos a los protagonistas, es decir, son varias las preguntas que se puede hacer a una noticia publicada. Como ya se ha dicho, la elección recayó sobre las primeras páginas con la secuencia de la noticia dentro del periódico, los personajes citados en las noticias sobre inmigrantes/migraciones, las fuentes, la existencia de entrevistas, fotos, gráficos, y el tono de la noticia: este dato suministrado por medio de la presencia de adjetivaciones, comparaciones, establecimiento de relaciones entre hechos y/o personajes, identificación y calificación de los sujetos de la acción ${ }^{3}$.

Para componer la muestra analizada fueron elegidos dos diarios distribuidos gratuitamente en Barcelona: Metro y ADN. La elección de Metro se basa en el hecho de ser producto de una multinacional y estar presente en más de 20 países en Europa, América del Norte y del Sur y Asia, con una media metropolitana de lectores de más de 18 millones, teniendo el $70 \%$ de ellos menos de 45 años. En España posee una edición nacional y 14 regionales ${ }^{4}$. La edición catalana es publicada en catalán y castellano. Fue elegido exactamente por ser globalizado y porque podría reflejar, en la edición local, una cierta orientación editorial homogénea en relación a este asunto. Para verificar la existencia de este posible alineamiento editorial en relación a la problemática de las migraciones, fueron analizados también las ediciones de Lisboa y de París, estos dos a partir de las ediciones en formato PDF disponibles en Internet ${ }^{5}$.

El otro periódico que compone la muestra de esta investigación es $A D N$, periódico local fundado en 2006 con sede en Barcelona y que se define como parte de la generación de los periódicos del siglo XXI. Fue creado para

\footnotetext{
2 Es necesario esclarecer que esa investigación aborda sólo el material efectivamente publicado, y que podría ser ampliada con abordajes complementarios que incluyan las rutinas productivas y la apropiación e incorporación de los contenidos vehiculados.

${ }^{3}$ De acuerdo con el instrumental analítico ofrecido por el Análisis del Discurso, ese tono no es fruto de la subjetividad del observador, pero está presente y puede ser capturado por medio de la identificación de los usos de los elementos verbales y gramaticales. De todas formas, conviene esclarecer que el Análisis del Discurso funciona, en esta investigación, como un complemento de las indagaciones sugeridas por Van Dijk.

4 Alicante, Aragón, Bilbao, Canarias, Castela, Catalunya, Castilla y La Mancha, Elx, Galicia, Madrid, Málaga, Metrosol, Sevilla y Valencia.

${ }^{5}$ Datos extraídos del site del periódico: www.metropoint.com
} 
[...] cubrir las necesidades de los millones de personas que necesitan información puntual veraz y objetiva. Frente a la mera exposición de la noticia, trabajamos para ofrecer contenidos elaborados y reflexivos con reportajes propios y un especial interés por el fotoperiodismo, y promovemos activamente la participación de los lectores, tanto en la edición en papel como en la versión online. [...] ADN es un diario liberal que defiende los valores básicos de la democracia y el progreso social. No está adscrito a ninguna organización política o religiosa y pretende contar con lectores de distintas ideologías. Refleja todas las posiciones, salvo las que defienden el uso de la violencia o promueven la discriminación racial o sexual ${ }^{6}$.

El período de análisis se extendió por tres semanas, entre los días 5 y 23 de marzo, con un total de 15 días en 3 semanas seguidas. Tal período fue elegido por no estar incluido en ningún calendario especial de eventos, ya sea político, cultural o social, ningún festivo o conmemoración que pudiese desviar las atenciones para algún fenómeno o acontecimiento específico. Con excepción de Metro París, en el cual la campaña presidencial ocupaba las primeras páginas de los periódicos -de todos ellos y no sólo de la prensa gratuita- hecho que, de cierta forma, fue determinante para corroborar una de las hipótesis de la investigación. Como el acceso a la edición portuguesa y francesa se hizo por medio electrónico, el período investigado se extendió por una semana más, hasta el día 26 de marzo, pues algunas de las ediciones electrónicas de Metro París estaban inaccesibles, lo que hubiera podido disminuir sensiblemente su presencia en la composición de la muestra.

\section{MEDIOS E INMIGRACIONES: UNA RELACIÓN DELICADA}

En los 15 días que compusieron las muestras seleccionadas no fueron encontradas muchas menciones a extranjeros, inmigrantes, o migraciones en las primeras páginas de los periódicos. Lo que equivale, entonces, a no merecer titulares de periódicos. ¿Cuándo y en qué circunstancia ese tema merece ser puesto en la portada? Ésta es la primera pregunta que la investigación intenta contestar.

En Metro Catalunya, durante el período analizado, apenas 4 noticias referentes a inmigrantes o migraciones fueron destacadas o puestas en la portada. El 9 de marzo, en un recuadro en el lateral izquierdo de la tapa surge la foto de Amina Lawal con el siguiente subtitulo: ahora vuelvo a tener amigos ${ }^{7}$. La noticia trae foto y entrevista, en la que cuenta su historia y en otro recuadro se explica: una invitada atípica - o sea, iletrada, pobre, africana y musulmana. El 14 de marzo aparece lo siguiente: 8.000 niños son forzados a prostituirse. Un recuadro en la primera página invita a la lectura de la noticia en la página 8 (Sección España). La noticia se publica a propósito de un encuentro internacional sobre "Explotación Sexual Comercial Infantil (ESCI)" e informa de que la mayoría de las víctimas proceden de Colombia, Brasil, República Dominicana, Marruecos, Nigeria, Sierra Leona y los Balcanes.

\footnotetext{
6 Informaciones retiradas del site del periódico: www.diarioadn.com/quienessomos [Consulta: 30 de marzo de 2007].

${ }^{7}$ Amina Lawal es una mujer nigeriana que fue salvada de la muerte por apedreamiento gracias a un movimiento que se difundió por Internet y ayudó en su absolución por el tribunal islámico. Estuvo presente en el II Encuentro España y África: Mujeres por un mundo mejor, realizado en Madrid.
} 
La presencia de los inmigrantes y del procesos de inmigración en la prensa...

El día 22 de marzo la noticia, publicada en un recuadro informa de lo siguiente: la policía recibe 44 denuncias por abusos racistas. El titular es en castellano, pero la noticia está en catalán -Les denuncies per racisme contra els Mossos disparen- lo que confiere a la noticia un carácter eminentemente local, a pesar de ser motivada por las celebraciones del Día Internacional contra el Racismo y la Xenofobia. Los datos referentes a las denuncias son suministrados por SOS Racismo. Al mismo tiempo en que publica el relato detallado de una injustificada agresión contra un marroquí, la noticia menciona como causa, no la xenofobia, sino una posible falta de preparació dels agentes en termes d'immigració, según la portavoz de la ONG mencionada.

En el mismo día, la gran materia de la portada es: El precio de los pisos obliga a compartirlos. Los datos informan de que la demanda de viviendas compartidas aumentó entre un 23 y un $30 \%$. Estudiantes y extranjeros son los principales colectivos que recurren a esta modalidad de arriendo, seguidos por las personas con contratos de trabajo inestables. La fuente de la noticia fue el presidente de la Asamblea de Comprar casa de Barcelona y un profesor de Asesoría y consultoría Inmobiliaria de la Universidad de Barcelona. Los entrevistados son tres jóvenes, supuestamente españoles, porque sus nacionalidades no fueron explicitadas, lo que sí sucede frecuentemente con los extranjeros.

En $A D N$ Barcelona los extranjeros aparecen directamente en la portada dos veces, en un total de cinco. La primera de ellas en una materia sobre jugadores africanos y en otra sobre denuncias de agresiones a extranjeros. En las otras dos materias la referencia a inmigrantes es encontrada en el cuerpo del texto, en el interior del periódico, y no en las noticias destacadas en la tapa.

Puede leerse: Detenidos tres responsables del local Bailén 22 por presunto proxenetismo (12 de marzo). La materia trae fotos y destaca que Los agentes arrestaron en la operación a tres prostitutas brasileñas (de un total de 61 que había en el local). La noticia se refiere a fuentes policiales y a algunos testimonios de vecinos.

En 13 de marzo el titular es La Eurocámara quiere erradicar el engaño y el abuso a jugadores africanos. En la sección de deportes los títulos son: Tráfico de jugadores: la Eurocámara quiere frenar la llegada masiva de africanos engañados por agen$t_{e} s^{8}$. La noticia narra comparativamente historias de vida de algunos jugadores que conocieron el éxito con la gran mayoría que hoy se encuentra en la miseria. Este tipo de narrativa conduce el lector a extraer sus propias conclusiones a partir de historias ejemplares, que favorecen un modelo anticipado de interpretación. En realidad, la noticia destaca las historias particulares en perjuicio de las informaciones objetivas sobre las medidas tomadas por la Eurocámara.

La misma noticia sobre los niños y prostitución recibe de $A D N$, el 14 de marzo, otro tratamiento. Aquí el titular es Turismo sexual en el extranjero y en la noticia interior es El $20 \%$ de turistas de Occidente busca sexo. Segundo, la madrina de la ONG In-

\footnotetext{
8 Es importante esclarecer que no fueron computados como temas relacionados con la migración la presencia de deportistas, o de celebridades de cualquier área de actuación, ya que esas personas se distinguen de la masa de inmigrantes y casi nunca son consideradas de la misma forma.
} 
tervida afirma que no hay que culpar a la gente de allí, sino a la gente que vive en países desarrollados y que va a los que no lo son en búsqueda de sexo con niños. La materia promueve una gran ambigüedad de significados, una vez que pone una foto con dos chicas con apariencia muy joven, tranquilas y sonrientes con el subtitulo Bailarinas buscan clientes en un bar de Pattaya, Tailândia.

Las otras dos noticias de la tapa que conducen a extranjeros son, la primera, Educación sin velo en Reino Unido, en ella se hace referencia a la posibilidad en las escuelas prohibir la utilización del velo a sus alumnas. Aunque la noticia informe de que en España todavía no hay debates sobre el tema y que cada comunidad autónoma puede decidir sobre su uso o no, la sección Xprésate (exprese su opinión) coloca la opinión de una lectora: cualquier día habrá conflictos por el uso del velo en alguna escuela. Entonces tendremos que mostrar si existe o no integración.

La noticia remite también al Liceo francés Al Kindi, en Lyon, que es una escuela musulmana en Francia, también objeto de atención del Metro París, como se verá más adelante.

Finalmente, en el 22 de marzo, coincidentemente con la noticia sobre racismo, aparece La mitad de las denuncias por agresiones a extranjeros salpican a los Mossos, la gran materia de la portada (EUROPA: seis razones para seguir amando a la Unión 50 años después) ofusca e impide cualquier impacto mayor que el asunto podría haber tenido. Utilizando la misma fuente, SOS Racismo, la noticia alerta sobre el preocupante aumento de los supuestos casos de abusos. En la foto, un hombre negro, coloca su marca (la mano mojada de tinta) en un panel colocado en la Rambla Santa Mónica. Son entrevistados los portavoces del SOS Racismo y de los Mossos d'Esquadra. Al contrario de Metro, no se incluye la narración de ningún caso concreto.

La noticia da secuencia en otra sección, titulada: Tolerancia a medias y empieza con la afirmación de que los españoles aceptan a los inmigrantes, pero mejor lejos que cerca. La convivencia se acepta mayoritariamente en diferentes ámbitos de la vida [...] pero los porcentajes bajan según crece la intimidad de la relación. Más adelante, la secretaria de Estado de Inmigración afirma que no existe motivo para alarma en referencia a la celeridad en la llegada masiva de extranjeros en España.

Metro Lisboa durante los 15 días de la investigación no incluyó ninguno titular en la portada o referencia al inmigrante o migraciones en el periódico. Ésa también puede ser una ausencia sintomática o también indicar que no hubo, en el período investigado, ningún caso que justificase la presencia de inmigrantes en las primeras páginas.

En Metro Paris el análisis se extendió por una semana más debido a los fallos en el acceso a la edición electrónica. Así, las cuatro semanas cubiertas por la pesquisa dispusieron de 15 ediciones, como los demás periódicos, como se puede ver a continuación.

De los cuatro diarios analizados, Metro París se reveló como el que da mayor destaque a los temas relacionados con la inmigración, lo que puede ser percibido por el mayor número de páginas, utilización de fotos y gráficos y también por el contenido 
La presencia de los inmigrantes y del procesos de inmigración en la prensa...

de las noticias, que va cambiando en la medida en que se aproxima la fecha de las elecciones presidenciales. Así, de las portadas y publicación de las noticias en las secciones más generales (Francia, por ejemplo) las noticias van siendo transferidas para las páginas de política.

La observación de la secuencia de los reportajes puede comprobar la politización del tema. El 5 de marzo se publica Imigration: la France coupée en deux (Inmigración: Francia cortada al medio $)^{9}$. Gran noticia de portada que presenta el resultado de una investigación realizada por Metro/IFOP (Institut Français de Opinion Publique) indicando que el $49 \%$ de los franceses son favorables a la inmigración en general, mientras que el $51 \%$ no lo son. La idea que prevalece es la de la buena gerencia de las entradas de extranjeros en el sentido de permitir apenas aquellos que puedan contribuir al desarrollo de la economía del país.

Un recuadro llama la atención sobre la noticia Lycée musulman: Al Kindi fait ça rentrée (Liceo musulmán: Al Kindi reabre), después de seis meses de batalla administrativa para funcionar y suministrar enseñanzas religiosas.

El 8 de marzo se publica un gran reportaje conmemorativo del día internacional de la mujer en el Special Journée internationalle de la femme, donde se presentan historias de vida (en su mayoría son pequeños relatos con fotos) en los que a pesar de aparecer sólo una mujer identificada como marroquí, algunas mujeres parecen ser inmigrantes o descendientes: dos son negras y una se llama Rachida, nombre de origen árabe.

En el ejemplar del 15 de marzo se puede leer Discrimination à l'embauche: il vaut mieux s'appeler Dupont (Discriminación en la contratación: es mejor llamarse Dupont [nombre típicamente francés]). Noticia extensa, con fotos, gráficos que, a partir de una investigación realizada por el Bureau International du Travail, denuncia la ilegitimidad de la preferencia por candidatos que tengan alguna característica que los identifica como inmigrantes ${ }^{10}$, especialmente si provienen del Magreb o de África sub-sahariana (Afrique noire, en el original).

En el 19 de marzo la presencia de los sin papeles no merece mayores destaques. Apenas un recuadro informa en pocas líneas de que Des sans-papiers investissen um temple (Sin papeles cercan un templo).

Entre los días 26 y 30 de marzo el enfoque cambia ${ }^{11}$ : de relatos de acontecimientos para el centro de la campaña política. Tres son las noticias de portada en el mismo día:

1. Identité nationale: mais quelle mouche les a donc piques? (Identidad nacional: ¿que mosca les picó?) Una gran noticia que discute, a propósito de la propuesta del

\footnotetext{
9 Todas las traducciones fueron hechas por la autora.

10 Sería extrapolar los limites de ese trabajo entrar en la discusión sobre emigración en Francia, pero son puestas en la misma categoría aquellos descendientes de la tercera generación y que, legalmente, son franceses.

${ }^{11}$ No se pudo tener acceso por medio electrónico a las ediciones de los días 21-23 de marzo, los archivos estaban damnificados.
} 
candidato Sarkozy de crear un ministerio de inmigración y de identidad nacional, cuestiones como nacionalismo, identidad nacional e inmigración, con las respectivas propuestas de los candidatos para solucionar el problema.

2. Thuram: 'le foot n'est que lê reflet de la societé' (Thuram: el fútbol no es más que reflejo de la sociedad). El jugador africano lamenta que la sociedad francesa sea tan poco reactiva al racismo actual. Uno de los pocos reportajes en que se da la palabra al inmigrante que efectivamente sufre las reacciones racistas.

3. Sans-papiers: la polemique continue (Sin papeles: la polémica continúa). Recuadro de llamada para la noticia de más de media página, con foto sobre las detenciones de inmigrantes sin papeles en la puerta de la escuela de los hijos. La protesta y la detención de la directora de la escuela son las razones de la polémica.

El 27 de marzo se publica Les musulmanes ont leur bikini (Las musulmanas tienen su bikini). Aparece un recuadro con la llamada para página interior, sección Mundo. Materia de media página con gran foto y un reportaje irónico sobre la creación del burkini, un traje de baño culturalmente correcto, creado por una estilista australiana, y que permitirá a las mujeres musulmanas realizar actividades acuáticas. La entrevistada es la estilista y dice que lo llamado maillot islamique (bañador islámico) recibió la bénédiction du mufti d'Australie (beneplácito de la autoridad religiosa de Australia). La foto muestra sonrientes bañistas cubiertas desde la cabeza hasta los pies corriendo en una playa desierta.

En los tres días siguientes (28, 29 e 30 de marzo), los disturbios causados por la entrada de una persona sin el debido billete en la Estación del Norte en París ocupa toda la atención: Bataille rangée gare du Nord (Batalla organizada en la Gare du Nord). Gran noticia de portada con secuencia en la página 2 (Sección Francia) con el gran título: Scènes de chaos à Paris (Escenas de caos en París). En un primer momento, los subtítulos afirmaban que une centaine de jeunes ont affronté la police hier dans les sous-sols de la gare parisienne (una centena de jóvenes afrontó la policía ayer en el subsuelo de la estación parisina). Asimismo, se publican fotos del enfrentamiento y del encarcelamiento de una persona negra.

En los dos días siguientes la noticia continúa en la portada, pero indican que sigue en la sección Política: Poltique: la campagne en gare du Nord (Política: la campaña en la Gare du Nord) (29/3). Ya no son los jóvenes los protagonistas, sino un ciudadano del Congo de 32 años en situación irregular, según fuentes policiales. Aparece una foto de una persona presa y dos candidatos, Sarkozy y Segolène, con sus respectivos comentarios ${ }^{12}$.

Ya en el día 30 el recuadro informa: Gare du Nord: l'avocat de l'interpellé contredit Baroin (Gare du Nord: abogado de interpelado contradice Baroin). Se trata de

\footnotetext{
12 Sarkozy aprovecha para manifestarse contra la regularización de todos los sin papeles y contra aquellos que se colocan favorables a los que no pagan sus pasajes.
} 
La presencia de los inmigrantes y del procesos de inmigración en la prensa...

una noticia de media página en que el abogado del congolés informa de que su entrada en Francia ocurrió hace más de 20 años en un proceso de reagrupación familiar, lo que es un procedimiento legal. La misma noticia muestra, en un recuadro, que el $40 \%$ de los franceses se dicen escandalizados y el $40 \%$ se dicen preocupados con los acontecimientos, según una encuesta hecha por la empresa OpinionWay. La noticia muestra también algunas secuencias de acciones policiales efectuadas contra inmigrantes en las puertas de las escuelas diciendo que la directora no sufrirá represalias por defender el padre de un alumno que vinieron a detener en la salida de las clases (noticia del día 26 de mayo).

\section{EXTRAÑOS EN EL NIDO: INMIGRANTES EN LA COMUNIDAD EUROPEA}

El análisis del material publicado reveló que los asuntos relacionados con inmigrantes o la inmigración correspondieron a las hipótesis propuestas en el inicio del trabajo. Así, se comprueba que existe un juego de visibilidad/invisibilidad. Las diversas formas que asumen la discriminación y el rechazo al diferente, sea cual sea éste, ocurre, antes de nada por medio de un juego de visibilidad/invisibilidad, de medias palabras y de insinuaciones, por medio de acusaciones o imputaciones explícitas. Así, la cuestión de la invisibilidad también debe ser considerada cuando se trata de observar el retrato que los medios de comunicación nos ofrecen de esos colectivos.

Por otro lado es importante conocer cuál es la visibilidad dada a determinada categoría de individuos, cuál es el tratamiento valorativo atribuido; en suma, cuándo y en qué circunstancias aparece y cómo aparece en los medios de comunicación. Además, desde la perspectiva del concepto del tratamiento de la información, su importancia reside en el hecho de que los medios, como grandes constructores culturales, son capaces de elaborar modelos de interpretación del mundo de forma que sean fácilmente asimilables y se vuelvan referencias que van a pautar sus opiniones, elecciones, conductas. Siguiendo a Van Dijk, el poder y las ideologías no están 'en' el texto, sino expresadas, manifestadas, construidas o legitimadas por el texto (Van Dijk, 1997: 65).

En lo que se refiere a los textos publicados, las miradas de los periódicos gratuitos a los inmigrantes van del abordaje étnico, curioso, al extrañamiento que causan las diferentes costumbres y religiones y a la resistencia explícita cuando se trata del control sobre las políticas públicas.

En este sentido, las revelaciones más importantes se deben a las informaciones obtenidas a partir de Metro París. Inicialmente, la incorporación de este periódico debería ser útil desde el punto de vista del control de la investigación, pero a medida que avanzaba la campaña electoral problema de la inmigración apareció en el periódico de manera bastante elocuente y con mucha frecuencia. De hecho, las discusiones sobre inmigración en Francia se tornaron uno de los ejes principales sobre los cuales se pautaron las disputas presidenciales ${ }^{13}$. En lo cotidiano, la problemática cuestión migratoria es abordada aparentemente como cualquier otra, a partir de la importancia que se confiere a los acontecimientos cuyos protagonistas sean inmigrantes y casi siempre con una perspectiva local, con algún hecho o evento que justifique la atención periodística. En este caso, aunque no se quiera hablar de que existe una cierta mala voluntad y un cierto preconcepto en los abordajes, ellos ex- 
plotan cuando se pone en cuestión políticas públicas que teóricamente podrían afectar los rumbos de la nación.

Podemos resaltar que el punto de vista de ese medio coincide con los discursos hegemónicos que consideran los procesos migratorios, las políticas de integración de los inmigrantes de acuerdo con los parámetros de las tendencias teórico-políticas multiculturales, con todo aquello que ellas engendran de posturas xenófobas disimuladas bajo el manto de la tolerancia de las diferencias culturales. Para Zizek, el multiculturalismo es la forma ideal del capitalismo global (2007: 56), al concebir todas y cada una de las culturas locales como cosas del Otro, que se debe conocer y respetar, siempre que cada uno permanezca en su espacio propio sin invadir las fronteras sociales. Es, en suma, la afirmación de la propia superioridad del sujeto universal para quien todos los demás son Otros.

Ese nuevo medio de comunicación no parece decidirse, todavía, a avanzar algunos pasos en dirección a la postura intercultural ${ }^{14}$, en dirección al universal y al intercambio horizontal y enriquecedor para las relaciones sociales. Evidentemente, sin negar las posibles tensiones negociadas en el cotidiano de la convivencia urbana. Esos serían pasos decisivos, una vez que se cree que los medios de comunicación tales como los aquí investigados, gratuitos, distribuidos personalmente, más próximos al lector que los otros grandes medios de comunicación, son más favorables a los procesos de dinamización cultural, más propensos a poner en la agenda de las discusiones cotidianas otras maneras de percibir a el otro.

\section{REFERENCIAS BIBLIOGRÁFICAS}

BAUMAN, Z. Confianza y temor en la ciudad. Vivir con extranjeros. Barcelona: Arcádia, 2006.

LITA, R. La prensa local y la prensa gratuita. Castelló de la Plana: Publicaciones Universidad Jaume I, 2002.

MAINGUENEAU, D. Novas tendências em análise do discurso. Campinas: Pontes, 1997.

ORLANDI, E. P. A linguagem e seu funcionamento. Campinas: Pontes, 2006.

SOLÉ, C. Birsl, U. Migración e interculturalidad en Gran Bretaña, España y Alemania. Barcelona: Anthropos, 2004.

\footnotetext{
$\overline{13}$ En las elecciones municipales realizadas en España este último 27 de mayo, también se puede verificar la cuestión de la emigración como elemento de campaña. Los periódicos estuvieron repletos de declaraciones xenófobas e, inclusive, algunos analistas indican que el partido Plataforma por Catalunya, dirigido por un franquista destacado consiguió aumentar su expresividad gracias al tema emigración y al voto joven. Ver Metro Catalunya, 29 de mayo de 2007, p. 5.

14 Para el concepto de interculturalidad, ver SOLÉ, C.; BIRSL, U. Migración e interculturalidad en Gran Bretaña, España y Alemania.
} 
La presencia de los inmigrantes y del procesos de inmigración en la prensa...

VAN DIJK, T. Racismo y análisis crítico de los medios. Barcelona: Ediciones Paidós Iberica, 1997.

ZIZEK, S. En defensa de la intolerancia. Madrid: Sequitur, 2007.

\section{Breve semblanza de la autora}

Maria Luiza Martins de Mendonça es doctora en Comunicación y profesora de la Facultad de Comunicación y Biblioteconomía de la Universidad Federal de Goiás. Esta investigación fue realizada con apoyo de la Capes/MEC-Brasil, en pasantía posdoctoral en el grupo de investigación MIGRACOM, del Departamento de Comunicación Audiovisual de la Facultad de Ciencias de la Comunicación de la Universitat Autónoma de Barcelona. Sus investigaciones tratan sobre temas relacionados con la diversidad cultural.

(Recibido el 20-11-07, aceptado el 21-03-08) 